\title{
DERECHO DE FAMILIA, SUCESORIO Y REGÍMENES MATRIMONIALES
}

\author{
Susana Espada Mallorquín \\ Profesora de Derecho Civil \\ Universidad Adolfo Ibáñez
}

LA DENUNCIA FALSA POR VIOLENCIA INTRAFAMILIAR COMO CAUSA JUSTIFICADA DE Desheredación del ar. $1208.1^{\circ}$ Del $C$ C. Corte Suprema, 21 de septiembre DE 2017, ROL 79128-2016.

En 2007 Ricardo A.B.A. contrajo matrimonio con Cristina J.S. y resultado de esta unión nació su hija Josefa V.B.J. El 15 de octubre de 2010 se produce la separación de hecho del matrimonio por la infidelidad de Cristina; eso sí, el 29 de octubre de 2010, Cristina deduce acción de violencia intrafamiliar, fundándola en que durante quince años Ricardo la violentaba de forma permanente con maltratos psicológicos tales como: insultos verbales, menoscabos como mujer, amenazas de agresión y expulsión de la casa. Ricardo resultó inocente en ese proceso, por cuanto los hechos comunicados no fueron probados, rechazándose la denuncia. En octubre de 2013, Ricardo deja la casa familiar, quedando en ella Cristina y Josefa.

Posteriormente, en julio de 2014, Ricardo otorgó testamento abierto en una notaría de Villarrica, instituyendo como única heredera de todos sus bienes a su hija Josefa y en la cláusula sexta de dicho testamento procedió a desheredar a Cristina, fundando su actuar en la injuria grave que cometió en contra de su honor, al haberlo denunciado como autor de violencia intrafamiliar, querella desestimada por no haberse acreditado el daño causado producto de la violencia. Así la cláusula sexta del testamento señalaba:

"Declaro además que desheredo a mi cónyuge doña Cristina J. S. cédula de identidad [...], por cuanto ha cometido injuria grave en contra de mi honor al haberme denunciado como autor de violencia intrafamiliar, según consta en la causa Rit 303 del año 2013 del Juzgado de Familia de Villarrica. En dicha causa, faltando a la verdad, estipuló que en forma permanente y durante quince años fue víctima de maltratos sicológicos de mi parte, consistentes en insultos verbales, menoscabos como mujer, amenazas de agresión y expulsión de la casa, hechos que fueron desestimados en dicha causa". 
Fallecido Ricardo, Cristina interpone demanda en juicio ordinario de reforma del testamento contra su hija Josefa y solicita que se modifique el referido testamento, específicamente en lo que respecta a la cláusula sexta del mismo, con el objetivo de que se le reconozca su calidad de legitimaria y se repare la lesión que está sufriendo en relación con la legítima rigorosa de la herencia sobre la cual tiene derecho. La parte demandada contestó solicitando su rechazo por cuanto la acción acometida por la ahora demandante en contra del causante por violencia intrafamiliar significó para el testador un daño moral devastador, que le afectó gravemente, constituyendo un caso de injuria atroz, ya que se basó en hechos falsos y no probados, desestimándose por ello la acción deducida. Por ello la causal de desheredamiento es legalmente procedente y, por tanto, la acción de reforma de testamento debe ser desestimada.

El Juzgado de primera instancia rechaza la demanda, pues considera justa la causa de desheredación por injuria grave al considerar probada la falsedad de la acusación de violencia familiar realizada contra el testador. Así en su considerando vigésimo noveno tuvo en vista el considerando sexto de la sentencia dictada en la causa sobre violencia familiar que estableció:

"[...] el informe del Centro de la Mujer señala que no hay daño en la denunciante, que tiene red de apoyo, respecto a la situación de la hija señala que no está vulnerada, no hay maltrato que afecte la integridad de la niña".

De igual forma, dicho sentenciador de primera instancia tuvo por ciertas las declaraciones de las testigos R.M. y N.V. (art. $384 \mathrm{~N}^{\circ} 3$ del CPC) que coinciden en señalar que la denuncia por violencia intrafamiliar de su propia esposa afectó física y psicológicamente al testador, atendido, además, el estado de salud que aquejaba a Ricardo. Ambos afirmaron el dolor inmenso que sufrió el testador por la difamación plasmada por su cónyuge con quien convivió quince años, después de tener una hija en conjunto pese a todas las dificultades que implicaba y por tener que dejarla a ella en la casa familiar, sin poder convivir junto a su hija.

La demandante interpone recurso de apelación y la Corte de Apelaciones de Temuco acoge la demanda de reforma del testamento, ya que en su considerando duodécimo establece:

"Es un hecho de la causa y de los antecedentes tenidos a la vista, que el requisito del art. $1209 \mathrm{CC}$ no se da en la especie ya que, por un lado, en la causa referida a la denuncia por violencia intrafamiliar, el juez la desestima por falta de prueba y no hace calificación alguna de la existencia de una denuncia temeraria o carente de fundamento, situación que en estos propios autos tampoco ocurre ya que no existe declaración del Tribunal de primera instancia en orden a dar por establecida la existencia de la causal (como tampoco los intervinien- 
tes solicitan su declaración), sino que se limita a rechazar la acción interpuesta incluso, declarando que la demandante tuvo motivos plausible para litigar, criterio, que, por lo demás esta Corte comparte, lo que sumado a los demás argumentos señalados precedentemente, justifican la revocación de la sentencia...”.

Se recurre a la Corte Suprema de casación en el fondo argumentando que se habrían infringido los arts. 1207, $1208 \mathrm{~N}^{\circ} 1$ y 1209 del $C C$. La Corte Suprema acoge el recurso de casación y dicta sentencia de reemplazo donde se considera que la denuncia falsa de violencia intrafamiliar interpuesta por su cónyuge es una justa causa de desheredación por constituir una injuria grave hacia la persona, el honor y los bienes del testador.

\section{FUNDAMENTO, EXCEPCIONALIDAD Y REQUISITOS DE LAS CAUSALES} DE DESHEREDACIÓN

En la presente sentencia, la Corte Suprema parte destacando que ante la existencia de asignatarios forzosos en nuestro ordenamiento, la acreditación de la concurrencia de una causal de desheredación debe ser especialmente rigurosa, ya que sirve para justificar la privación a los legitimarios de todo o parte de su legítima (art. 1207 del CC).

En este sentido, podemos afirmar que la protección que el legislador otorga a los asignatarios forzosos se justifica porque se presume que estos asignatarios van a tener una conducta acorde con los cercanos lazos familiares que le unen con el causante, basados en un respeto recíproco. Son los lazos familiares unidos a un comportamiento de respeto mutuo lo que justifica la atribución patrimonial ${ }^{1}$. Es por ello que el desheredamiento solo estará justificado en casos excepcionalmente graves, como sanción a la mala conducta de los legitimarios y, por ello, la Corte Suprema afirma que las causales de desheredación son "una media extrema para casos excepcionales" (cons. quinto).

Respecto a este punto quisiera hacer una precisión. Es cierto que la doctrina chilena afirma que no hay más causas de desheredamiento que las contempladas en el art. 1208 del $C C$, aun cuando la conducta que el heredero haya podido llevar a cabo pueda ser considerada más grave de las allí señaladas e igualmente, se sostiene que por ser causales excepcionales y limitativas deben interpretarse restrictivamente, no admitiendo interpretaciones amplias o aplicaciones analógicas².

En mi opinión, el hecho de que se exija una interpretación restrictiva de las causas taxativas no puede significar una exigencia tan estricta que impida cualquier tipo de interpretación de dichas causales por parte del juez. Respecto de la interpretación estricta y amplia de las disposiciones excepcionales, Karl

\footnotetext{
${ }^{1}$ Elorriaga de Bonis (2010), p. 487.

${ }^{2}$ Op. cit., p. 489.
} 


\section{LARENZ señala:}

"Se tiene que evitar que mediante una interpretación demasiado amplia de las disposiciones excepcionales o mediante su aplicación analógica la intención del legislador se trueque finalmente en lo contrario a ella. Pero esto no significa que la disposición excepcional haya de interpretarse tan estrictamente como sea posible o que la analogía quede excluida en todo caso. Aquí es decisiva de nuevo la razón por la que el legislador ha exceptuado precisamente esos casos"3.

Por ello, de acogerse esta argumentación a pesar de afirmar el carácter extremo y excepcional de las causales de desheredación, considero que esto no impide a los jueces interpretar las causales de desheredación adecuándose al tiempo y a la realidad social actual en la que se aplican, sin que ello se considerase una interpretación prohibida por su carácter extensivo ${ }^{4}$.

Hecha esta aclaración, en su considerando quinto la Corte señala los requisitos que son precisos que concurran para que válidamente proceda el desheredamiento:

" $1^{\circ}$. Que se haga por una disposición testamentaria expresa (artículo 1209). Debe hacerse por medio de una disposición testamentaria, en que el testador expresamente ordene que el legitimario sea privado del todo o parte de su legítima. Se trata de una medida de rigor y ella debe expresarse de un modo claro y terminante; en caso de duda sobre la voluntad del testador, no existiría el desheredamiento.

$2^{\circ}$. Que se funde en alguna de las causas indicadas por la ley (art. 1208).

$3^{\circ}$. Que la causa legal en que se funda el testador sea expresada específicamente en el testamento (art. 1209). No basta que se diga en el testamento que se deshereda a tal o cual legitimario; es menester que se exprese específicamente en el testamento la causal legal en que se funda el desheredamiento. Deberá, pues, referirse el testador expresamente a alguna o algunas de las cinco causales enumeradas en el artículo 1208. Esta es una solemnidad especial que la ley quiere que se cumpla, el desheredamiento hecho sin expresión de causa no vale, y,

$4^{\circ}$. Que la causal de desheredamiento debe ser probada judicialmente en vida del testador, o por los interesados después de su muerte (art. 1209)".

Respecto de los mencionados requisitos, en la sentencia objeto de ese comentario dos son los principales problemas que se plantean. Por un lado, la necesidad de precisar que es una injuria grave en el sentido de la causal

\footnotetext{
${ }^{3}$ Larenz (2001), pp. 352-353.

${ }^{4}$ En este mismo sentido véase BETTi (2009), pp. 105-108.
} 
establecida en el art. $1208.1^{\circ} \mathrm{del} C C \mathrm{y}$, por otro, que se determine cuándo se considera probada en esos casos la causal mencionada, así como su mención testamentaria y su posible revisión casacional.

\section{EL CONCEPTO DE INJURIA GRAVE} DEL ART. $1208.1^{\circ}$ DEL $C C$

Como pone de manifiesto la Corte Suprema en el considerando octavo de la presente sentencia:

“[...] nuestro Código Civil no ha dado una definición ni describe siquiera lo que debe entenderse por injuria grave o atroz, que permitan determinar cuáles son los elementos que autorizan para calificar de grave o atroz la ofensa o injuria hecha a una persona. La jurisprudencia ha señalado que la injuria consiste en un hecho ejecutado o dicho proferido en deshonra o menosprecio de otro. El móvil de la injuria es siempre el perjuicio, molestia o daño que se trata de infligir al injuriado, a fin de satisfacer alguna venganza, odio o resentimiento de parte del injuriante (RDJ. Tomo 13, sec. $\left.1^{\mathrm{a}}, \mathrm{p} .13\right)$. También ha sostenido que para dar por establecido la existencia de un acto injurioso y, sobre todo, de un acto que pueda consistir injuria grave, se necesita que medie una intención dolosa de parte del que lo ejecuta, dirigido a perjudicar, molestar o dañar al injuriado (RDJ. Tomo 64, sec. $1^{\mathrm{a}}$, p. 176)".

En este sentido la doctrina también considera la que el término "injuria grave" no puede tomarse con una significación penal (art. 416 del Código Penal), sino con un significado más genérico que hace referencia a un daño o perjuicio, como se define en el art. 44 del $C C^{5}$. Según el citado precepto la culpa grave en el ámbito civil equivale al dolo y este consiste en la intención positiva de inferir injuria a la persona o propiedad de otro.

Luego, es posible interpretar que podrá ser desheredado justamente quien haya realizado un comportamiento susceptible de causar un grave daño o menoscabo intencional en contra de alguna de las personas que se mencionan en el art. $1208.1^{\circ}$ del $C C$, pues dicho comportamiento será susceptible de ser calificado como injuria grave.

\section{LA FALSEDAD DE LA ACUSACIÓN DE VIOLENCIA INTRAFAMILIAR}

La determinación de si existe un daño y la gravedad del mismo es una cuestión de hecho que deberá ser apreciada por los tribunales del fondo. En este

\footnotetext{
${ }^{5}$ Elorriaga de Bonis (2010), p. 492.
} 
sentido y teniendo en cuenta los hechos relatados en el fallo, cuando existe una falsa acusación de violencia intrafamiliar, la gravedad del daño de esa falsa acusación derivará de que la única motivación de llevarla a cabo sea causar -con una intención dolosa por parte de quien acusa- un daño, perjudicar y molestar al injuriado, lesionando su honra, a fin de satisfacer con ello alguna venganza, odio o resentimiento.

En nuestro caso, en la contestación a la demanda se señalaba que el único objetivo de la acusación de violencia intrafamiliar fue dañar al causante gravemente en aquello que para él es del máximo valor: su honor. $\mathrm{Al}$ imputarle acciones de poca hombría, de vileza y acoso psicológico cobarde y permanente, que no corresponden de un hombre hacia su mujer, fue la imputación más dañina que para el honor de Ricardo pudieron realizarle.

$\mathrm{Al}$ respecto, considero que los tribunales deben tener claro que para aplicar la concurrencia de esta causal de desheredación, lo esencial es cerciorarse de la falsedad de la acusación de violencia intrafamiliar y, por ello, que su única finalidad sea esta intención dolosa de dañar mediante injurias al causante. Por lo tanto, el constatar meramente el hecho de que no se logró probar la violencia intrafamiliar no siempre va a implicar que la acusación de quien la realiza sea falsa y que esto justifique una desheredación por injuria. La ausencia de prueba de la violencia no es sinónimo de la falsedad de la acusación. Eso sí de constatarse en los hechos que la demanda por violencia 342 se funda en hechos falsos y que la intención de su interposición es deshonrar, afrentar, envilecer y desacreditar al demandado, será un comportamiento susceptible de calificarse como injuria grave que justifique una desheredación de aquel que lo realice.

Sin embargo, que lo relevante a los efectos de aceptar la denuncia falsa como causal de desheredación sea la constatación por parte de los tribunales de la falsedad de la misma no significa que se tenga que existir, como afirma la sentencia recurrida de la Corte de Apelaciones de Temuco, "una declaración objetiva del juez que afirme el carácter temerario y carente de fundamento de la demanda de violencia intrafamiliar" (considerando primero de la sentencia de la Corte Suprema). Si el juez de instancia a raíz de los hechos probados logra constatar la falsedad de la denuncia de violencia, así como el daño a la honra del testador (art. $1208.1^{\circ}$ del $C C$ ), podría declarar la desheredación como justa, a pesar de que no exista una declaración del juez que califique la interposición de la demanda como temeraria y carente de fundamento.

En estos casos de acusación de violencia intrafamiliar, quizá podría resultar oportuno establecer como criterio la exigencia de que en el juicio o en la resolución se constatase la condena en costas al desheredado (art. 144 del $C P C$ ). Como sabemos, el tribunal puede eximir de dichas costas cuando se hayan tenido motivos plausibles para litigar, de lo cual debe hacerse declaración expresa en la resolución. Cuando se condena en costas respecto de la acusación de violencia intrafamiliar y el juez expresa que dicha condena se basa en la ausencia de un motivo plausible para litigar, tenemos un elemento 
de peso para poder afirmar la falsedad de la acusación, sin necesidad de tener que exigir que un juez declare la temeridad de la acción. El comportamiento injurioso que justifica la desheredación del legitimario es la falsedad de la acusación, que en parte se acredita por la ausencia de un motivo plausible para acusarle ante los tribunales de hechos de extrema gravedad como son los considerados en la violencia intrafamiliar.

Luego no toda ausencia de prueba de los hechos constitutivos de violencia intrafamiliar justifica la desheredación del acusador; pero tampoco solo podrá causar injurias aquella acusación de violencia que haya sido temeraria en sus términos. Eso sí, probada la falsedad de una acusación de violencia intrafamiliar -lo que puede presumirse si existe condena en costas- es posible desheredar al acusador, pues, sin duda, dicha acusación falsa provoca un grave daño a la honra del causante.

\section{LA PRUEBA DE LOS HECHOS CONSTITUTIVOS DE INJURIA GRAVE}

Como pone de relevancia la sentencia de la Corte Suprema en su considerando noveno:

"Que las causas que autorizan el desheredamiento se apoyan en hechos, que deben ser acreditados por los que tienen interés en que la voluntad del testador sea cumplida, en este caso, el peso de la prueba corresponde al demandado. Por lo demás, procesalmente, quien afirma es quien debe probar el hecho, como norma general. En suma, debe probarse que los hechos en que se apoyó el testador eran ciertos".

En este sentido también la doctrina ${ }^{6}$ complementa esta afirmación señalando que procesalmente, para los fines del art. 1209 del $C C$, los hechos constitutivos de la injuria grave los determinan soberanamente los jueces del fondo, es decir, los de la instancia; pero la precisión de si esos hechos tienen la gravedad suficiente requerida por ley para justificar una desheredación es una cuestión de calificación que quedaría sujeta al control de casación.

Por lo tanto, una vez identificada la causal de desheredación es necesaria la referencia al factum cuasal desheredatorio ["haber cometido injuria grave contra el testador en su persona, honor o bienes (art. $1208.1^{\circ} \mathrm{del} C C$ )"], pero también del factum probans respecto del factum probandum ${ }^{7}$ (expresando la causa en el testamento y probado judicialmente en vida del testador o por los interesados tras el fallecimiento, exart. 1209 del $C$ C).

\footnotetext{
${ }^{6}$ Domínguez y Domínguez (2011), p. 1093.

${ }^{7}$ Martinez Gallego (2006), p. 1620.
} 
En este caso, el testador en la cláusula sexta de su testamento hacía referencia expresa a los hechos de los que falsamente se le acusaba ${ }^{8}$, por lo tanto, esos son los hechos que deben quedar probados en la instancia y, en casación, la Corte podrá entrar a calificar si los mismos son suficientemente graves para constituir una causa justa de desheredación. Así, en la sentencia que se comenta, en casación se estimó en los considerandos decimotercero y decimocuarto:

\begin{abstract}
“[...] el acto ejecutado en desdoro del testador, consistente en la denuncia indebida y sin fundamento por violencia familiar de su cónyuge, unido a la infidelidad de la misma, ha debido ser hecha con la intención de deshonrar, afrentar, envilecer, desacreditar, hacer odiosa, despreciable o sospechosa la conducta de éste, elementos suficientes para considerarse injuriado. [...] Que, a la luz de lo expuesto en las consideraciones precedentes, no cabe más que concluir que se encuentra configurada la causa de injuria grave consagrada en el artículo $1208 \mathrm{~N}^{\circ} 1$ del Código Civil, la cual, además, ha sido probada durante el proceso y, al no establecerlo así los jueces de la instancia, han infringido lo dispuesto en los artículos 1208 causal la y 1209 inciso primero del Código Civil, por cuanto la causal ha sido válidamente probada en el juicio".
\end{abstract}

En este sentido, para calificar la gravedad de la injuria, la Corte Suprema tuvo en cuenta, por un lado, la sentencia dictada en la causa sobre violencia intrafamiliar que afirmaba la inexistencia de daño en la denunciante y en su hija; y, por otro, las declaraciones de testigos -que el sentenciador de primer grado tuvo por ciertas- y que coincidían en señalar que la denuncia por violencia intrafamiliar de la esposa afectó física y psicológicamente al testador, el dolor y aflicción padecidos por este, teniendo en cuenta su delicado estado de salud y el dolor inmenso que le supuso la difamación de su cónyuge con quien convivió quince años, después de tener una hija en común a pesar de la dificultades y de ahora tener que dejarla a ella en la casa familiar junto a su hija.

\title{
Bibliografía CITADA
}

Betti, Emilio (2009). La interpretación jurídica. Santiago: Legal Publishing. Domínguez Águila, Ramón y Ramón Domínguez Benavente (2011). Derecho sucesorio. Santiago: Editorial Jurídica de Chile. Tomo I.

\footnotetext{
${ }^{8}$ En este sentido se puede señalar que en nuestro Código Civilno está prevista la posibilidad de que sea el propio causante el que inicie un juicio en vida destinado específicamente a establecer la veracidad y certeza de los hechos que invoca para desheredarlo.
} 
Elorriaga de Bonis, Fabián (2010). Derecho sucesorio. Santiago: Abeledo Perrot Legal Publishing.

Larenz, Karl (2001). Metodología de la Ciencia del Derecho. Barcelona: Ariel Derecho. Martínez Gallego, Eva. (2006). "La desheredación”. Actualidad Civil. Nº 16, Tomo II. Madrid. 